\title{
In vitro UVB induced cellular damage assessment using primary human skin derived fibroblasts
}

\begin{abstract}
Nowadays there is a great deal of concern resulting from the impact of UV light on human skin especially when skin damage levels are predicted to rise due to ozone layer depletion. The skin acts as an important biological barrier, and plays an important physiological and immunological role. This study reports the UVB-induced effect on skin derived primary fibroblasts one of the most abundant cells in the dermis. Two time points, immediately and 24 hour post UVB exposure were used to measure the magnitude of UVB-induced cytotoxicity. The induced cell membrane damage was assessed by neutral red (NR) dye uptake while cellular metabolic activity was assessed by the 5-(3-carboxy-methoxyphenyl)2-(4.5-dimethylthiazolyl)-3-(4-sulphonyl) (MTS) cytotoxicity assay. A correlation was found between the MTS and neutral red (NR) assay in measuring UVB-induced cellular damage in exposed skin fibroblasts cultures immediately post exposure. These findings indicated that doses higher than $2.2 \mathrm{~J} / \mathrm{cm}^{2}$ were needed for the immediate expression of measurable cell membrane damage by the assays systems used. This should not indicate that no damage is triggered by lower irradiation levels, since our observations $24 \mathrm{~h}$ post UVB-irradiation of the same cells showed cellular membrane damage for lower doses $(0.7 \mathrm{~J} /$ $\mathrm{cm}^{2}$ ) by comparison to immediately post exposure. The assessment of cellular metabolic activity indicated that MTS displayed a higher sensitivity in detecting early cell damage by comparison to the NR assay. The UVB induction follows a dose dependent response, and the cellular damage induced by exposure is best-measured $24 \mathrm{~h}$ following exposure.
\end{abstract}

Volume I Issue 4 - 2015

Christian Khalil

Department of Natural Sciences, Lebanese American University (LAU), Lebanon

\section{Correspondence: Christian Khalil, Lebanese American University, Lebanon, Tel +96109547262,}

Email Christian.khalil@lau.edu.lb, c.khalil@unsw.edu.au

Received: June 09, 2015 | Published: October 14, 2015

Keywords:cells, viability, uvb, mts, neutral red, cytotoxicity

\section{Introduction}

The reduction of the ozone layer triggered a major concern about the harmful effects of environmental exposure to solar radiation. Among the spectrum of UV radiation emitted by the sun UVB is thought to be the major cause of skin damage and long-term health risks. The effects of UVB (290-320nm) radiation on human skin can be seen as acute (sunburn and inflammation) ${ }^{1,2}$ or chronic (photo aging and skin cancer). ${ }^{1-3}$ The acute effects of UVB are thought to be mediated by cytokine production leading to cell death (early apoptosis). ${ }^{4-7}$

The human skin is composed of a variety of cells including skin fibroblasts. These cells by virtue of their location and numbers in the dermis could be used as possible indicators of cellular damage caused by UVB irradiation. The synergistic interaction of the dermal fibroblasts with epidermal keratinocytes in vitro linked by prostaglandin $\mathrm{E}_{2}$ upregulation has been suggested as an indicator of cellular interactions and their contribution to the overall organ response. ${ }^{8}$ The measurement of cell viability and cytotoxicity in skin fibroblasts may also provide useful information on the levels of UVB required to induce damage.

The main focus of this research was to identify the most sensitive assay for measuring the early signs of UVB cytotoxicity and to determine the most suitable techniques to achieve this purpose.

\section{Materials and methods}

\section{Cell cultures preparation}

Primary fibroblast cell cultures were derived from human skin biopsies (Children's Hospital West mead (Australia)) and maintained in short term cell culture. Cells were subcultured as adherent cells in $75 \mathrm{~cm}^{2}$ tissue culture flasks with $0.2 \mu \mathrm{m}$ vented seals (Falcon). The culture media consisted of color free Dulbeco's modified eagle medium (DMEM): RPMI 1640 (1:1) purchased from Sigma Chemicals, supplemented with 5\% fetal calf serum (Trace Bioscience), and 3\% Sigma antibiotics (penicillin (10,000units), streptomycin (10mg) and L-glutamine $(200 \mathrm{mM})$ ). The cell lines were cultured at $37^{\circ} \mathrm{C}$ at subconfluence in a humidified incubator set to a mixture of $5 \% \mathrm{CO}_{2} / 95 \%$ air. Cells viability was over $95 \%$ as measured by Tryptan blue dye exclusion.

Confluent cells in log phase of growth were released from the bottom of the culture flask using Trypsin EDTA, and then washed three times with cell culture medium. This was followed by a cell count before the cells were seeded on 24 well plates and incubated overnight to allow cells to reattach to the bottom of plates before UVB irradiation.

\section{Cellular UVB irradiation}

For UVB irradiation medium was replaced with HBBS, the coverlids of the 24 well micro titer plate (Falcon) removed and cells exposed to UVB irradiation $\left(3.92 \times 10^{-4} \mathrm{~W} / \mathrm{cm}^{2}\right)$ from a 6 lamps (FS40212) supplied by Wayne Electronics (Somerby, Australia). The output of the lamps was measured by an IL-1700 research radiometer (International Light, Newburry Port, MA).

Previous studies reported that UVB exposed cells produce cytokines when exposed to $300 \mathrm{~J} / \mathrm{m}^{2}$ and this dose is within the range of UVB exposure in human skin. ${ }^{9}$

In this study we exposed cells to different times under a bank of UV lights. The conversion of the time of exposure from $\mathrm{W} / \mathrm{cm}^{2}$ into $\mathrm{J} /$ $\mathrm{cm}^{2}$ could be performed using the following formula: $\mathrm{T}(\mathrm{min})=\mathrm{J}\left(\mathrm{cm}^{2}\right)$ $\mathrm{X} 16.7 /\left(\mathrm{mW} / \mathrm{cm}^{2}\right)$ 
Therefore, in order to reach the physiological range of UVB exposures in human skin $\left(300 \mathrm{~J} / \mathrm{m}^{2}\right)$ we need to expose the cells to a certain period of time (T) to an intensity of $3.92 \times 10^{-4} \mathrm{~W} / \mathrm{cm}^{2}$ obtained by using a lamp bank (6 lamps).

$$
\begin{aligned}
& \mathrm{T}(\mathrm{min})=\left(\mathrm{J}\left(\mathrm{cm}^{2}\right) \mathrm{X} 16.7\right) /\left(\mathrm{mW} / \mathrm{cm}^{2}\right) \\
& =(0.03 \times 16.7) /(0.392) \\
& =1.27 \mathrm{~min}
\end{aligned}
$$

It should be noted that the distance from the light source to the exposed cell was $22 \mathrm{~cm}$ in this experimental setting. In the experimental approach adopted UVB exposure was divided into low and high doses based on the length $(\mathrm{T})$ of exposure.

Cells were irradiated with UVB doses ranging from $7.8 \mathrm{~mJ} / \mathrm{cm}^{2}$ to $5.6 \mathrm{~J} / \mathrm{cm}^{2}$ (Table 1).

Table I Exposure times recorded for the UVB exposed cells and the respective UVB dose delivered

\begin{tabular}{ll}
\hline Respective dose $\left(\mathrm{J} / \mathrm{cm}^{2)}\right.$ & Time of exposure (Time in minutes) \\
\hline 0.0078 & 0.33 \\
0.0156 & 0.66 \\
0.0312 & 1.33 \\
0.0625 & 2.66 \\
0.0860 & 3.66 \\
0.25 & 10.66 \\
0.70 & 30 \\
1.40 & 60 \\
2.11 & 90 \\
2.81 & 120 \\
5.63 & 240 \\
\hline
\end{tabular}

\section{Cytotoxicity Assessment}

Neutral red assay: The Neutral red (3-amino-7dimethyl-amino2methyl-phenazine hydrochloride) assay is a cell survival technique used to identify viable cells based on their ability to uptake the neutral red dye. This assay was used to measure the cytotoxicity upon UVB exposure. UVB cellular exposure will hinder dye uptake and this will be assessed using a micro titer plate reader using a $540 \mathrm{~nm}$.

The essay was performed in 24 well plates. The procedure followed consisted of the following steps:

\section{A. Immediately post UVB exposure}

i. Removal of exposure medium following cultures UVB exposure using a biological safety cabinet class III.

ii. Addition of $0.33 \%$ neutral red solution (Sigma Chemicals, USA) in an amount equal to $10 \%$ of the initial culture media volume.

iii. Cultures are returned into the incubator for a $2 \mathrm{~h}$ incubation period.

\section{B. $24 \mathrm{~h}$ post UVB exposure:}

i. Removal of cultures from UV exposure cabinet into laminar flow hood.

ii. Replacement of exposure medium (HBSS) with $200 \mu \mathrm{L}$ of culture media.

iii. Cells are respectively cultured for $24 \mathrm{~h}$ before the application of NR assay (step 1).

Media was removed $2 \mathrm{~h}$ post incubation and cells rinsed with HBSS. Upon washing cells were then rinsed for 1minute with NR Assay Fixative $\left(1 \%(\mathrm{wt} / \mathrm{v}) \mathrm{CaCl}_{2}: 0.5 \%(\mathrm{v} / \mathrm{v})\right.$ Formalin). The incorporated dye was then solubilized in a volume of NR solubilization solution $(1 \%(\mathrm{v} / \mathrm{v})$ Acetic acid: $50 \%(\mathrm{v} / \mathrm{v})$ Ethanol) equal to the original volume of the culture medium $(200 \mu \mathrm{L})$. Cultures were allowed to stand for 10 minutes at room temperature in a microplate rotator.

The absorbance of the wells was measured spectrophotometrically using the Lab system Multi scan MS (Finland) at a wavelength of $540 \mathrm{~nm}$. The background absorbance was measured at $690 \mathrm{~nm}$ and subtracted from the $540 \mathrm{~nm}$ measurement. This measurement allowed us to determine UVB-induced cellular membrane damage and the inhibitory capacity of cell culture to incorporate the dye upon UV insult.

MTS cytotoxicity assay: The Promega Cell Titer 96@ A Queo Non Radioactive cell Proliferation Assay was used to measure the cytotoxicity of UVB exposure by determining the number of viable cells in cultures. The MTS (3-(4, 5-dimethylthiazol-2-yl)-5-(3carbomeyhoxyphenyl)-2-(4-sulfophenyl)-2H-tetrazolinum) assay is based on the ability of viable cells to convert the soluble tetrazolium salt into a Formazan product by mitochondrial dehydrogenase. The assay will inform us on the mitochondrial dehydrogenase cellular damage and whether the observed level of damage could be correlated with the reduction of cell neutral red dye uptake upon UVB insult.

The MTS assay (Promega corporation) consisted in the addition of MTS solution prepared by mixing a solution of MTS $(42 \mathrm{mg}$ MTS powder in $21 \mathrm{ml}$ of DPBS $\mathrm{pH}$ 6.0-6.5) with a PMS solution $(0.92 \mathrm{mg} / \mathrm{ml}$ PMS in DPBS) to the cells to be tested in a ratio of 1:5. The MTS was then incubated with the cells for a period of $2 \mathrm{~h}$ and $24 \mathrm{~h}$ post exposure at $37^{\circ} \mathrm{C}$ in the dark. After the incubation period the cellular supernatant was removed and placed in a 96 well plates for measurement. The amount of reduced Formazan was assessed by measuring the optical density at $492 \mathrm{~nm}$ using a Lab system Multi scan MS plate reader. Data was plotted as a dose response curve with time of exposure versus absorbance reading.

\section{Statistical analysis}

The data were expressed as the mean and SD of 2 to 4 replicated wells. Statistical procedures and graphical analysis were performed using Microsoft Excel 7.0 software.

\section{Results}

\section{Determination of the UVB induced cytotoxicity on human kin fibroblasts using the MTS and NR assay}

The experimental investigations used skin fibroblasts cultures at a density of 50,000 cells $/ 100 \mu 1$ of media $(5 \%$ fetal calf serum $3 \%$ antibiotics) exposed to UVB doses $\left(0-5.6 \mathrm{~J} / \mathrm{cm}^{2}\right)$ with damage levels assessed by two cytotoxicity assays (Figure 1). 


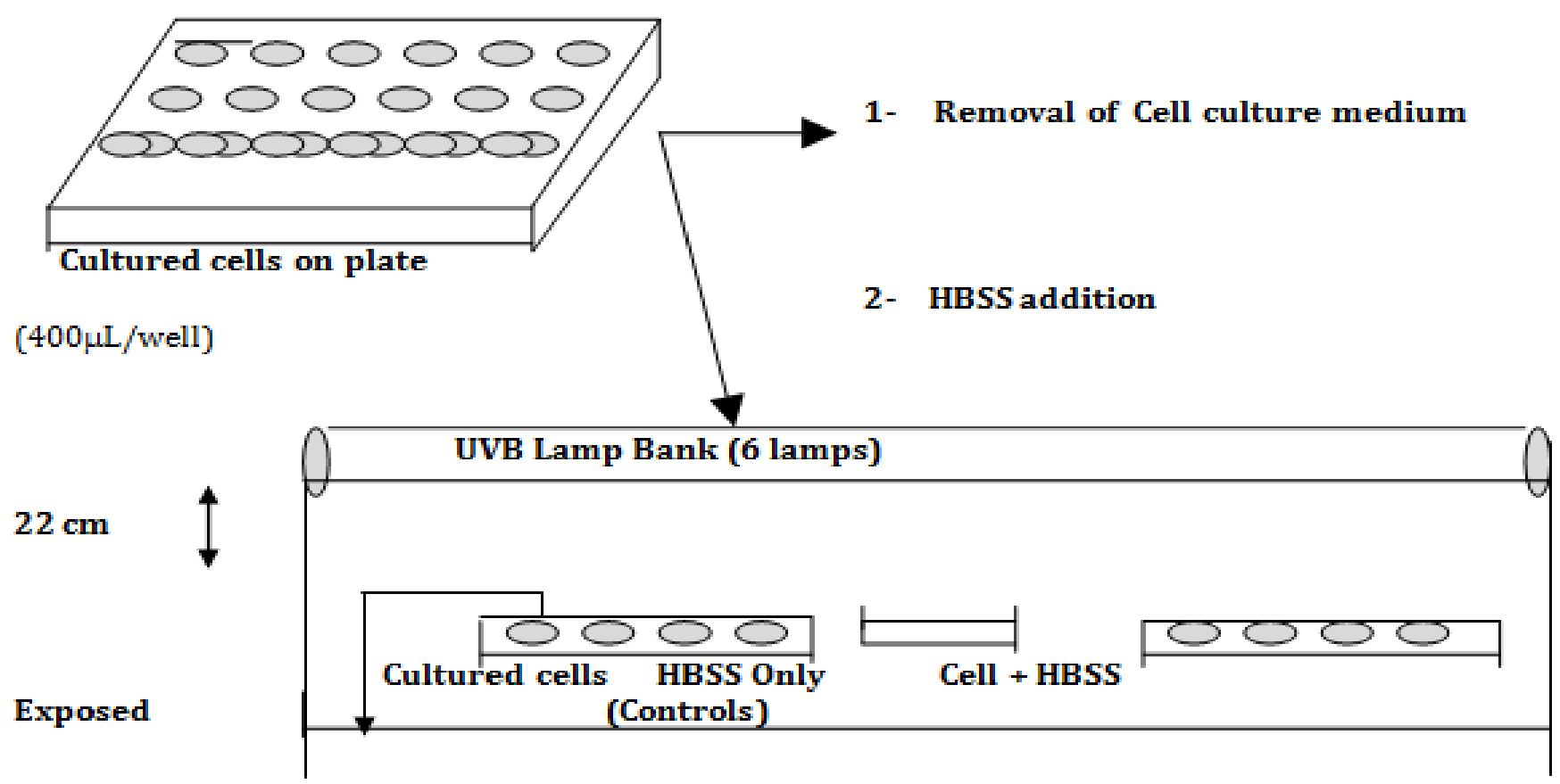

Figure I Schematic representation of the procedure used in UVB irradiation: Wells covered with opaque tape after variable exposure time Irradiated HBSS in contact with the cell monolayer collected for cytokine analysis and replaced with fresh media (for $24 \mathrm{~h}$ post exposure) or with MTS/ NR dye for immediate cytotoxicity assessment.

The MTS results in Figure 2 showed a dose response relationship between exposure and cellular mitochondrial dehydrogenase activity as measured by the MTS assay. A decrease in the mitochondrial activity was directly associated with increased UVB dose. The cell exposure to a dose of $2.1 \mathrm{~J} / \mathrm{cm}^{2}$ of UVB reduced the mitochondrial activity by more than $50 \%$, while at $5.6 \mathrm{~J} / \mathrm{cm}^{2}$ of UVB we witnessed a reduction in activity by $80 \%$.

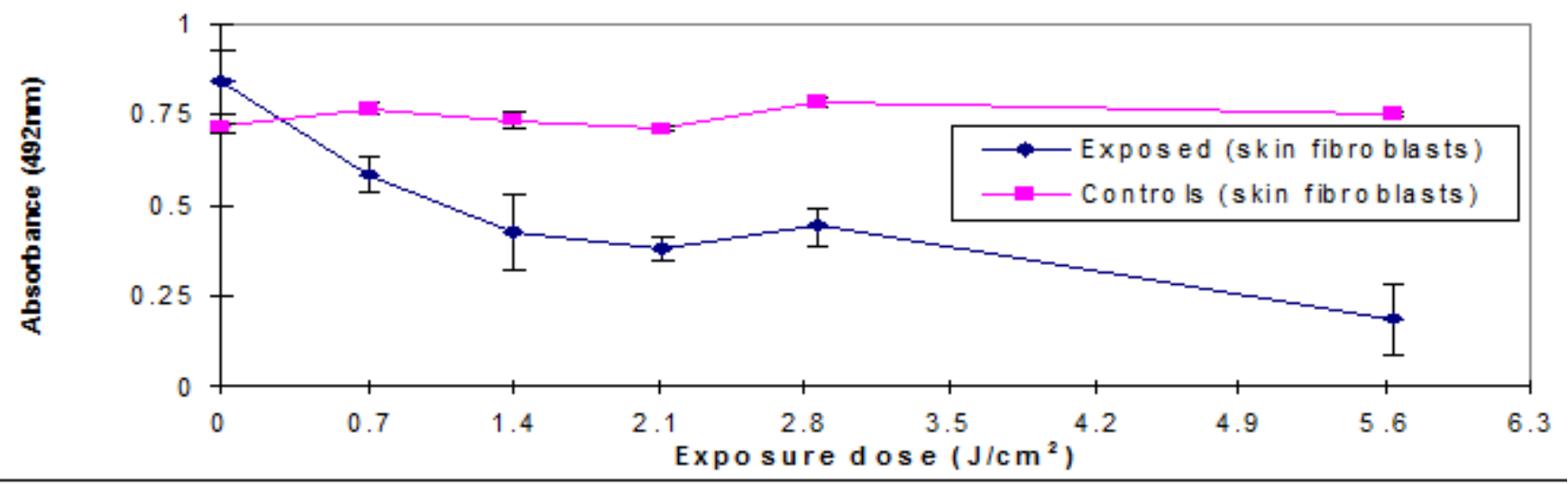

Figure 2 Relationship between UVB dose and mitochondrial lactate dehydrogenase activity: Cell media was removed and replaced with $400 \mu \mathrm{L}$ HBSS for UVB exposure. Dose response curve for UVB induced reduction of mitochondrial lactate dehydrogenase in skin fibroblasts cells as measured by the MTS cytotoxicity assay immediately upon exposure. Values are mean \pm SD of 4 replicates.

The relationship between UVB exposure and cellular viability was further investigated using the NR assay. The damage caused by UVB was assessed by determining the reduction in NR dye uptake by the lysosomes because cells with damaged cellular membranes leak and cannot retain the dye. ${ }^{10}$ The leakage results in reducing the NR dye uptake by damaged cells. The measured damage was at the cell lysosomal level which represents the primary target of the NR dye. NR decreased uptake by exposed cell could be directly related to UVB exposure. Figure 3 showed a decrease in the uptake of the dye upon exposure in both the UVB-exposed cells. The exposure of the cellular cultures to UVB doses $\left(2.1-2.8 \mathrm{~J} / \mathrm{cm}^{2}\right)$ decreased the dye uptake by more than $50 \%$.

We therefore hypothesized the existence of a potential correlation between membrane damage and reduced mitochondrial activity. Correlation analysis outlined in Figure 3.1 showed that there was a direct agreement between the MTS and NR assays in measuring damage extent $\left(\mathrm{R}^{2}=0.75\right)$. They were both measuring damage levels at different cellular compartments. The low $\mathrm{R}^{2}$ value recorded could be the result of different toxicity mechanisms triggered by UVB exposure and a possibility that the damage was not of the same magnitude on different cellular organelles. 
The results in Figure 3.2 also indicated that the MTS absorbance is not changing in a similar fashion like the NR which is an interesting finding. Membrane integrity is crucial for mitochondrial dehydrogenase activity. This could be explained by the reported radiation-induced decrease in mitochondrial enzyme activity caused mainly by peroxidation of membrane lipids and not to be due to direct damage by radiation to the enzyme molecule itself as reported in the literature. ${ }^{11}$ This might explain the delayed LDH activity reduction measured by the MTS assay $\left(5.6 \mathrm{~J} / \mathrm{cm}^{2}\right.$ compared to $2.8 \mathrm{~J} / \mathrm{cm}^{2}$ observed in NR assay).

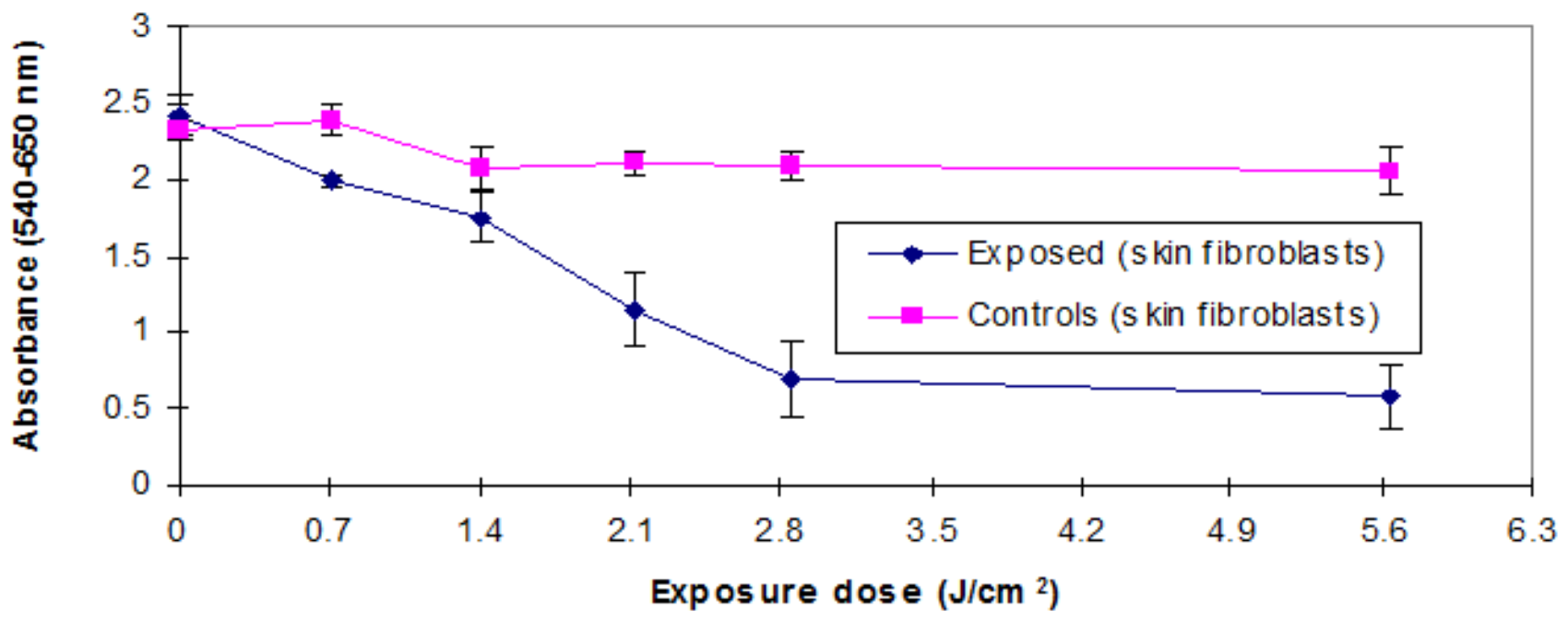

Figure 3.I Relationship between UVB dose and neutral red uptake in cultured skin fibroblasts as measured by the neutral red assay following exposure: Cell media was temporarily removed and replaced with $400 \mu \mathrm{L}$ of a HBSS solution. Cells were exposed to UVB doses ranging from 0 to $5.6 \mathrm{~J} / \mathrm{cm}^{2}$. Cell media was returned post exposure and cells subjected to the NR assay. Values are given as meanSD of 4 replicates.

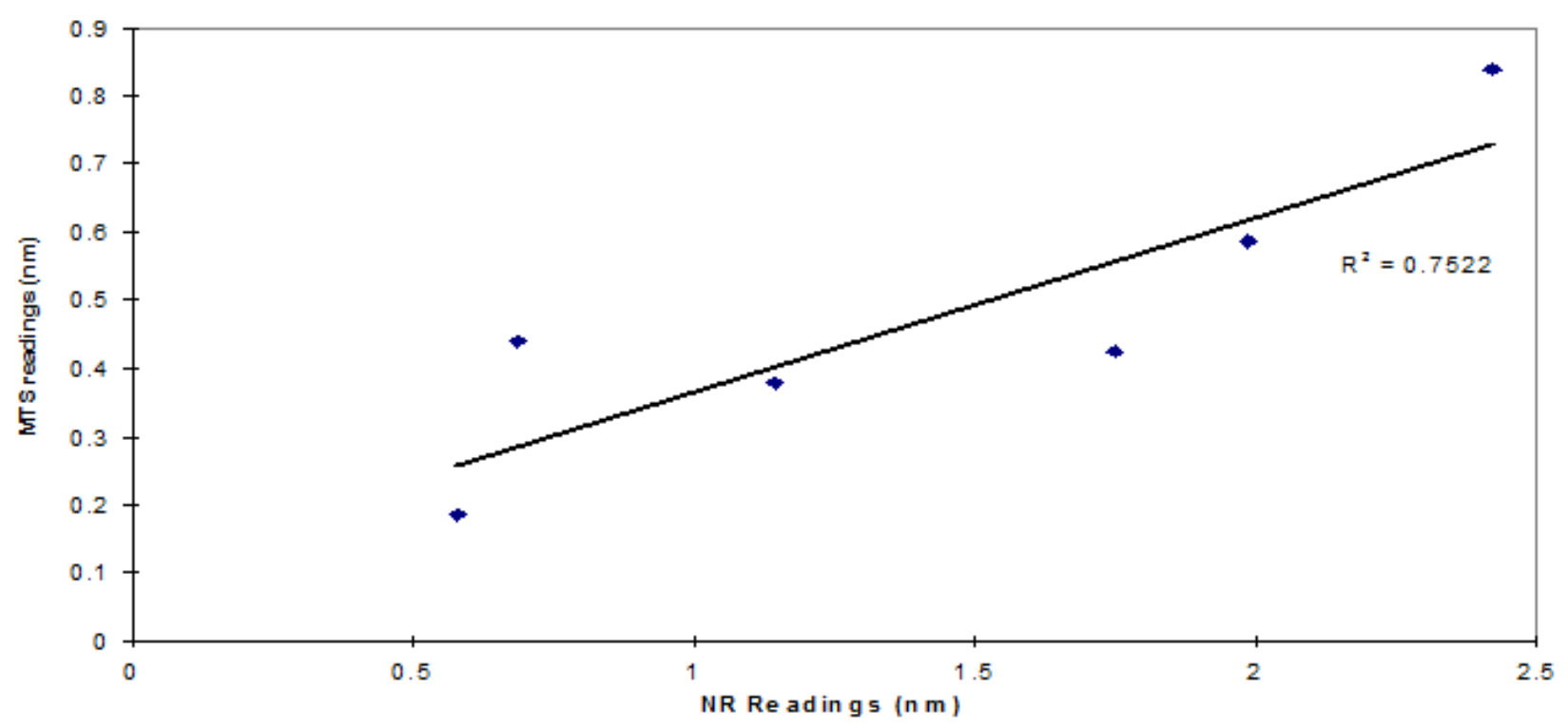

Figure 3.2 Correlation between MTS and neutral red assay in evaluation of UVB cell induced toxicity following exposure of skin fibroblast cells: The absorbance values recorded for exposed cells in Figure 2 and Figure 3.I are plotted together.The axis readings are in absorbance units (nm).

These findings led to exploring the damage caused by UVB exposure assessment $24 \mathrm{~h}$ post exposure and whether the same levels of damages were expressed. Primary skin fibroblasts $\left(46 \times 10^{3}\right.$ cells $/ 100 \mu \mathrm{l}$ ) were exposed to UVB and cultured for $24 \mathrm{~h}$ post exposure before cytotoxicity assays. The exposure of skin fibroblasts cells to UVB doses and their impacts on cellular viability $24 \mathrm{~h}$ post-exposure are outlined in Figure 4 \& 5 .

Cytotoxic results using the MTS assay $24 \mathrm{~h}$ post UVB exposure was illustrated in Figure 4 showed the sensitivity of the MTS test in detecting the effects of UVB radiation on cellular processes. By contrast, the NR assay (Figure 5) did not exhibit the same level of sensitivity in detecting cell membrane damage under the same exposure conditions. We observed immediate significant mitochondrial damage at low exposure levels while the lysosomal membrane damage needed higher exposure doses $\left(0.7 \mathrm{~J} / \mathrm{cm}^{2}\right.$ compared to $1.4 \mathrm{~J} / \mathrm{cm}^{2}$ observed in NR assay). No correlation could be established between the MTS and neutral red cytotoxicity test for UVB exposure of skin fibroblasts $24 \mathrm{~h}$ post exposure (Figure not shown). 


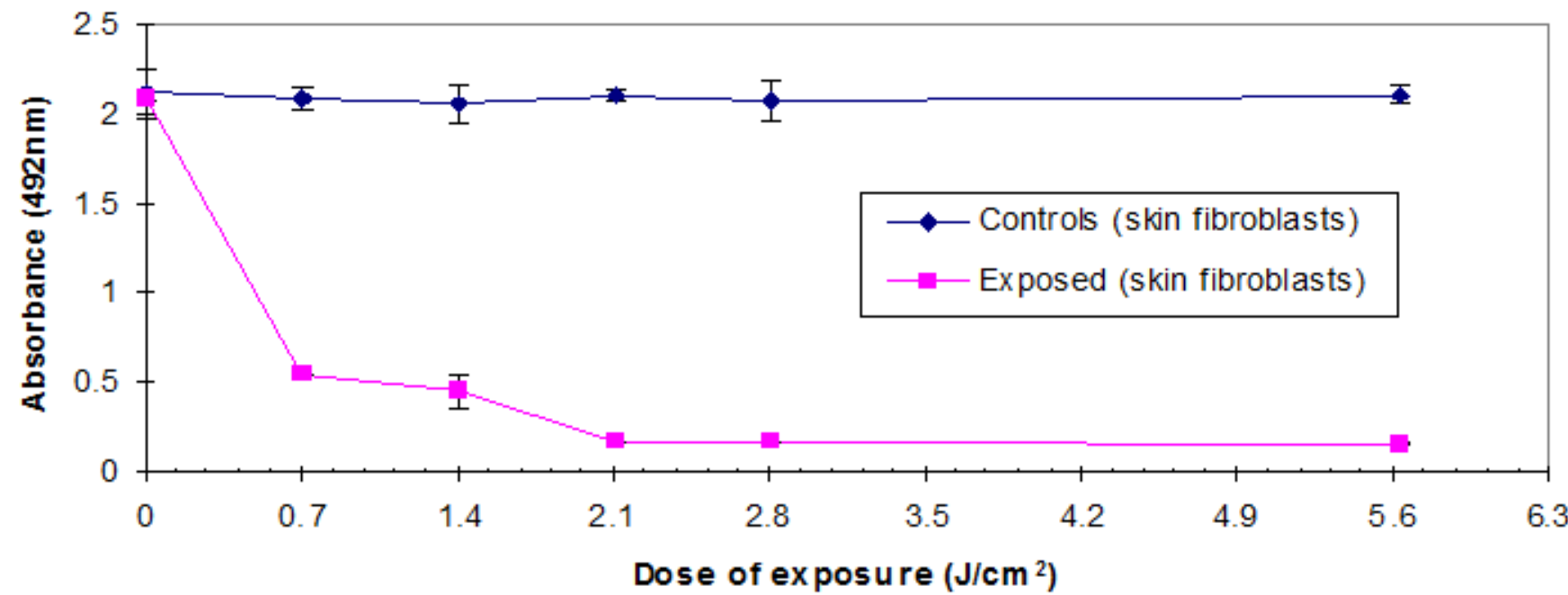

Figure 4 MTS assay on UVB exposed skin fibroblasts $24 \mathrm{~h}$ post exposure: UVB induced cytotoxicity in skin fibroblasts using the MTS assay $24 \mathrm{~h}$ post variable dose exposure. Cell media was substituted with HBSS for UVB exposure. Immediately post exposure HBSS was replaced with cell media and cells incubated for $24 \mathrm{~h}$ before MTS assay. Values are given as mean \pm SD of 4 replicates.

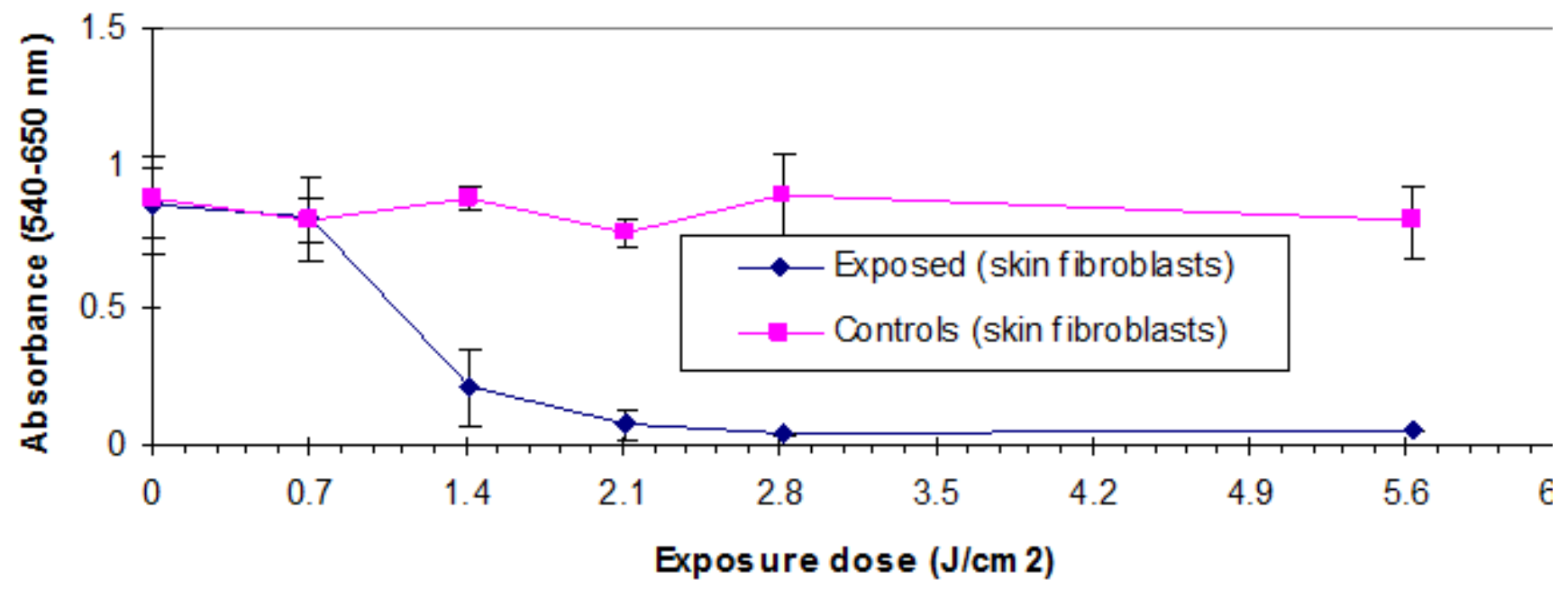

Figure 5 Cytotoxicity determination of UVB exposed skin fibroblasts using the neutral red assay $24 \mathrm{~h}$ post variable UVB dose exposure: The exposure procedure consisted of replacing the culture media with HBSS and subjecting the cells to UVB radiation. Immediately post exposure HBSS was replaced with cell media and cells were subjected to the NR test $24 \mathrm{~h}$ post exposure.Values are given as mean \pm SD of 4 replicates.

\section{Discussion}

The results indicated that the MTS and NR assays could detect mitochondrial and lysosomal damages triggered by UVB exposure in a dose dependent manner. It was evident from the MTS data that UVB exposure of skin fibroblasts cultures reduced the enzymatic mitochondrial lactate dehydrogenase activity by up to $80 \%$ for doses of $5.6 \mathrm{~J} / \mathrm{cm}^{2}$. Exposure of fibroblasts to UVB doses ranging from $0.7-5.6 \mathrm{~J} / \mathrm{cm}^{2}$ triggered an immediate decrease in the mitochondrial lactate dehydrogenase enzymatic activity in the exposed cells as measured by the MTS assay (Figure 2). This decrease in activity was more significant if the exposed cells were further incubated $24 \mathrm{~h}$ post exposure before assessing mitochondrial lactate dehydrogenase activity $^{10,12}$ (Figure 4).

The NR assay detected significant changes induced by the UVB doses ranging from $0.7-5.6 \mathrm{~J} / \mathrm{cm}^{2}$. The UVB exposure resulted in an immediate reduction in dye uptake by the exposed cells (Figure 3.1). Further $24 \mathrm{~h}$ incubation in fresh media of these UVB exposed cells showed a marked effect on cells dye uptake (Figure 5). The 24h data results agreed with the MTS results whereby the 2 assays could detect UVB induced damage although the MTS assay detected damage for doses as low as $0.7 \mathrm{~J} / \mathrm{cm}^{2}$ while the NR assay detected damage for doses as low as $1.4 \mathrm{~J} / \mathrm{cm}^{2}$. The inability of the neutral red assay to detect damage levels for doses of $0.7 \mathrm{~J} / \mathrm{cm}^{2} 24 \mathrm{~h}$ post exposure may be due to the nature of damage inflicted by irradiation which does not seem to affect cell membrane function as severely as it affects other cellular metabolic functions.

The correlation between membrane damage and reduction in mitochondrial activity resulting from UVB cell exposure was tested (Figure 3.2) and there was a direct agreement between the two techniques in measuring extent of damage $\left(\mathrm{R}^{2}=0.75\right)$ immediately post UVB exposure. This agreement between the two techniques could not 
be established $24 \mathrm{~h}$ post exposure possibly as a result of different cell organelles repair mechanisms, different rates of cell multiplication as a result of organelles damage triggered by UVB, or other variables. It was reported in the literature ${ }^{13}$ that UV-induced cellular apoptosis occurs via the p53/p21/bax pathway, with sequential increases in these genes in the epidermis being maximal at 12, 24 and $24-72 \mathrm{~h}$, respectively. ${ }^{14}$ Therefore, UV exposure may, by mutating a p53 gene, causing tumor initiation (DNA mutation) which could explain the higher sensitivity in damage measurement as reported by the MTS assay. ${ }^{13}$

The data generated indicated that the two methods used were suitable for testing the impact of UVB on cellular functions. We found that the tests have to be used together as they were measuring different end-points. They could be useful in detecting sunburn damage by pinpointing toxic responses at organelles levels. The detection of the early damage levels triggered by UVB exposure was best achieved $24 \mathrm{~h}$ post exposure. We therefore conclude that the MTS and NR were valuable tools for cellular damage assessment immediately and $24 \mathrm{~h}$ post exposure with the MTS assay measuring earlier cellular damage levels.

\section{Acknowledgements}

None.

\section{Conflict of interest}

The author declares no conflict of interest.

\section{References}

1. Bald T, Quast T, Landsberg J, et al. Ultraviolet-radiation-induced inflammation promotes angiotropism and metastasis in melanoma. Nature. 2014;507(7490):109-113.

2. Coffelt SB, de Visser KE. Cancer: Inflammation lights the way to metastasis. Nature. 2014;507(7490):48-49.

3. Kaur A, Thatai P, Sapra B, et al. Need of UV protection and evaluation of efficacy of sunscreens. Journal of Cosmetic Science. 2014;65(5):315345 .
4. Kim MJ, Woo SW, Kim MS, et al. Anti-photoaging effect of aaptamine in UVB-irradiated human dermal fibroblasts and epidermal keratinocytes. Journal of Asian Natural Products Research. 2014;16(12):1139-1147.

5. Fernandez TL, Van Lonkhuyzen DR, Dawson RA, et al. Characterization of a human skin equivalent model to study the effects of ultraviolet $\mathrm{B}$ radiation on keratinocytes. Tissue Engineering Part C Methods. 2014;20(7):588-598.

6. Aoki R, Aoki Yoshida A, Suzuki C, et al. Protective effect of indole-3pyruvate against ultraviolet $\mathrm{b}$-induced damage to cultured $\mathrm{HaCaT}$ keratinocytes and the skin of hairless mice. PLoS one. 2014;9(5):e96804.

7. Narayanapillai S, Agarwal C, Deep G, et al. Silibinin inhibits ultraviolet $\mathrm{B}$ radiation-induced DNA-damage and apoptosis by enhancing interleukin-12 expression in JB6 cells and SKH-1 hairless mouse skin. Mol Carcino. 2014;53(6):471-479.

8. Ghauri B, Manshaa M, Khalil C. Characterization of cytotoxicity of airborne particulates from urban areas of Lahore. Journal of Environmental Sciences. 2012;24(11):2028-2034.

9. Pathak MA. Sunscreens and their use in the preventive treatment of sunlight-induced skin damage. Journal of Dermatol Surg Oncol. 1987;13(7):739-750.

10. Bakand S, Winder C, Khalil C, et al. Toxicity assessment of industrial chemicals and airborne contaminants: transition from in vivo to in vitro test methods:a review. Inhal Toxicol. 2005;17(13):775-787.

11. Yukawa O, Miyahara M, Shiraishi N, et al. Radiation-induced damage to mitochondrial D-beta-hydroxybutyrate dehydrogenase and lipid peroxidation. Int J Radiat Biol Relat Stud Phys Chem Med. 1985;48(1):107-115.

12. Khalil C, Winder C. Surface water toxicity assessment by Ecotoxicological and in vitro toxicological assays. WIT Transactions on Biomedicine and Health. 2008;110:253-262.

13. Clydesdale G, Dandie G, Muller HK. Ultraviolet light induced injury: Immunological and inflammatory effects. Immunol and Cell Biology. 2001;79(67):547-568.

14. Ouhtit A, Muller HK, Davis DW, et al. Temporal events in skin injury and the early adaptive responses in ultraviolet-irradiated mouse skin. Am J Pathol. 2000;156(1):201-207. 